\title{
A role for capsaicin sensitive, tachykinin containing nerves in chronic coughing and sneezing but not in asthma: a hypothesis
}

\author{
J-A Karlsson
}

Sensory nerves with endings in the airway mucosa mediate respiratory protective reflexes such as coughing, sneezing, mucus secretion, and bronchoconstriction, which are common symptoms of airway disease. Studies in experimental animals suggest that these reflexes have unique afferent pathways, though these have been difficult to identify in man. One pharmacological tool that is increasingly used in studies of neural reflexes is capsaicin, the pungent agent of hot peppers. Capsaicin seems to excite rather selectively a population of tachykinin peptide containing, chemosensitive afferent nerves. ${ }^{12}$

In rodent airways capsaicin produces severe bronchoconstriction and a pronounced inflammatory response, which seems to be mediated by substance $P$, neurokinin $A$, and possibly other tachykinin peptides. ${ }^{3-6}$ Tachykinins contract human bronchi in vitro $^{78}$ and produce bronchoconstriction when inhaled by asthmatic subjects. ${ }^{9}$ The density of substance $\mathbf{P}$ immunoreactive nerves ${ }^{10}$ and expression of the neurokinin ${ }_{1}$ receptor gene $^{11}$ have been reported to be increased in the asthmatic lung. Consequently neuropeptide release, via an axon reflex, has been proposed to be particularly important in the pathology of asthma. ${ }^{12}$ The proinflammatory effects so apparent in rodents, however, cannot be reproduced even when high doses of capsaicin are repeatedly inhaled by normal or asthmatic subjects $^{6}$ and capsaicin sensitive nerves seem unlikely therefore to have a major role in asthma. Instead, experimental and clinical data indicate that their most important function in the human respiratory tract is to mediate protective reflexes. The hypothesis now is that hyperreactivity in these afferent nerves-that is, sensory hyperresponsiveness-contributes to respiratory symptoms in patients with chronic non-productive cough and nonallergic chronic rhinitis.

Discovery Biology,

Rhone-Poulenc Rorer,

Dagenham Research

Centre, Dagenham,

Essex RM10 7XS

J-A Karlsson

Reprint requests to:

Dr J-A Karlsson

Received 22 June 1992

Returned to author

29 July 1992

Revised version received

12 October 1992

Accepted 5 November 1992 man. ${ }^{14}$ Substance $P$ belongs to a family of structurally closely related peptides, including neurokinin $A$, neurokinin $B$, neuropeptide $K$, and neuropeptide gamma, which are derived from at least two different preprotachykinin genes. ${ }^{15}$ These tachykinins, and calcitonin gene related peptide, are present in a population of non-myelinated capsaicin sensitive afferent nerves. ${ }^{5}$

Capsaicin induced neuropeptide release is preceded by increased cation permeability over the cell membrane. In larger concentrations capsaicin is neurotoxic and rapidly causes death of nerve cells. The tachykinins act on neurokinin 1,2 , or 3 receptors (which have highest affinity for substance $P$, neurokinin $A$, and neurokinin $B$, respectively), located on airway and vascular smooth muscle, submucosal glands, parasympathetic nerves, and airway epithelium. ${ }^{16}$ In guinea pigs and rats tachykinin peptides produce bronchoconstriction, vasodilatation, plasma protein leakage from the tracheobronchial microcirculation, mucus secretion, and facilitation of cholinergic neurotransmission. ${ }^{56}$ These effects are mimicked by capsaicin, suggesting an important sensory efferent role for these nerves. Thus in rodent airways neuropeptides released from capsaicin sensitive sensory neurones, presumably via an axon reflex, ${ }^{17}$ have pronounced bronchoconstrictor and proinflammatory actions.

Interestingly, the most obvious responses to intravascular administration of tachykinins or capsaicin in the sheep, ${ }^{18}$ pig, ${ }^{19}$ dog, ${ }^{20}$ and cat $^{21}$ are a vasodilator response in the tracheobronchial circulation and mucus secretion. ${ }^{22}$ When present, airway smooth muscle contraction in rat, rabbit, ferret, and dog is largely mediated through parasympathetic cholinergic pathways. ${ }^{6}$ In the cat capsaicin produces a reflex bronchodilatation. ${ }^{23}$ Furthermore, plasma protein extravasation has not been observed in cat or dog airways. ${ }^{24}$ Hence the characteristic bronchoconstrictor and proinflammatory effects have not been confirmed in non-rodent animal species.

Sensory neuropeptides in human airways Human bronchi are contracted by tachykinin peptides in vitro, neurokinin A-but not substance $\mathrm{P}$-being more potent than methacholine and histamine..$^{72526}$ It has been more difficult to show bronchoconstriction in vivo. Maximum doses of inhaled substance $P$ are without effect on airway tone ${ }^{9}$ and when infused intravenously a predominantly cardiovascular response was obtained. ${ }^{27}$ Neurokinin $A$ is 10 times more potent than 
substance $P$ in vitro, which may explain why airways obstruction was induced when a large dose was inhaled by asthmatic subjects. ${ }^{9}$ The bronchoconstriction was inhibited partly by nedocromil sodium and partly by an antimuscarinic agent, indicating that neurokinin A did not act directly on the smooth muscle. ${ }^{28} 29$ In healthy and asthmatic subjects inhaled capsaicin caused only transient bronchoconstriction (for under a minute) which depends on a parasympathetic cholinergic reflex. ${ }^{30}$ Endogenous tachykinins, if released, are therefore unlikely to have any noticeable effects on airway tone in vivo.

It has been speculated that the shedding of epithelium that occurs in severe asthma and upper respiratory tract viral infections reduces airway neutral endopeptidase activity, which is present in the bronchial mucosa and is the major proteolytic enzyme for tachykinins. ${ }^{56}$ Consequently the "braking" mechanism would be absent in asthmatic subjects and endogenous tachykinins would be able to exert their proinflammatory effects uninhibited. Thiorphan, a neutral endopeptidase inhibitor, would thus be expected to increase basal tone (by potentiating the effect of endogenous tachykinins) and augment the effects of inhaled peptides in healthy subjects. In asthmatic subjects on the other hand no effect would be expected if neutral endopeptidase is absent.

Inhaled thiorphan, however, was found to have no effect on basal tone but to potentiate inhaled neurokinin $A$ to the same degree in healthy and asthmatic subjects. ${ }^{31} 32$ Nichol and coworkers ${ }^{33}$ studied the neutral endopeptidase inhibitor acetorphan on reflex bronchoconstriction induced by inhaled metabisulphite in asthmatic subjects. Metabisulphate acts partly via a non-cholinergic mechanism, but its effect was not altered by acetorphan (though weal and flare induced by substance $P$ were significantly potentiated in the same subjects). ${ }^{33}$ These experiments were conducted in subjects with mild asthma, and if shedding of epithelium is proportional to the severity of the disease, the effect could be more pronounced in severe asthma. The present data support the view that endogenous tachykinins are not important for regulation of bronchial tone in human airways in vivo. Clinical studies with the recently developed potent non-peptide neurokinin receptor antagonists, ${ }^{34} 35$ however, will provide further information on the role of tachykinin peptides in man.

The effects of local application of tachykinins and capsaicin on nasal air flow, leakage of plasma proteins, and secretion have been examined in the human nose. The nasal mucosa is readily accessible and, for example, mediator release and microvascular leakage can be measured non-traumatically. A dose of substance $P$ or calcitonin gene related peptide producing systemic vascular effects (vasodilatation) did not induce secretion or nasal blockage ${ }^{3637}$ or affect mucociliary clearance. ${ }^{38}$ Capsaicin, on the other hand, caused a burning sensation, pro- nounced sneezing, and secretion, ${ }^{139}$ patients with vasomotor rhinitis being particularly sensitive. ${ }^{39}$ Secretion induced by capsaicin can be blocked by a muscarinic antagonist and is thus due to a cholinergic parasympathetic reflex. ${ }^{39}$ Interestingly, capsaicin induced secretion from the human oral mucosa is also mediated through a cholinergic reflex. ${ }^{40}$ Despite administration of capsaicin directly on to the nasal mucosa, plasma protein extravasation and mediator release could not be detected. ${ }^{41}$

Interestingly, intradermal injection of capsaicin into human skin produced pain and a local vasodilator response (flare) but not oedema (weal). ${ }^{42} 43$ The flare is produced by sensory neuropeptides released through an axon reflex and, as in the airways, there is little evidence of a local inflammatory response to capsaicin. Tachykinin mediated changes in tracheobronchial and nasal blood flow is, however, a distinct possibility, which has not yet been studied in man.

Thus, whereas studies in rodents strongly emphasise the sensory efferent function of capsaicin sensitive sensory nerves, accumulating data indicate that at least two major effects-that is, bronchoconstriction and extravasation of plasma protein (as measured in the nose)-cannot be reproduced in human subjects. Likewise glandular secretion seems to be mediated via a cholinergic parasympathetic reflex rather than local release of neuropeptides.

Sensory afferent role for capsaicin sensitive nerves in man

Respiratory and cardiovascular reflexes are triggered by topical application of capsaicin. ${ }^{2}$ In guinea pigs, for example, pronounced coughing and sneezing are produced and these reflexes are mediated by afferent pathways that are separate from those underlying the bronchoconstrictor reflex. ${ }^{244}$ Coughing cannot be secondary to release of peptides because these do not themselves trigger cough and treatment with the neutral endopeptidase inhibitor thiorphan did not potentiate the cough response, though bronchoconstriction was increased. ${ }^{45}$ Already at low (nanomolar) doses aerosolised capsaicin causes pronounced coughing, sneezing, and secretion in man. Capsaicin induced cough is most probably mediated by tachykinins and C fibre afferents containing calcitonin gene related peptide with endings located in both central and peripheral airways. ${ }^{46}$ As in guinea pigs, in man this response seems not to be due to endogenous tachykinins acting on other lung afferents because coughing is not produced when these peptides are inhaled. ${ }^{9}$ It could be argued that coughing prevented the capsaicin aerosol from penetrating deeper into the lung to trigger bronchospasm. Several arguments, however, can be raised against this view. Firstly, in guinea pigs coughing and severe bronchoconstriction occur simultaneously. Secondly, other respiratory tract irritants, such as bradykinin, 
produce both cough and airway obstruction in asthmatic subjects. Finally, even when a small particle aerosol is inhaled into peripheral airways no bronchoconstriction is produced. ${ }^{46}$ Taken together, these findings suggest that the afferent function of capsaicin sensitive nerves in the airways is less species specific, and these nerves are likely to subserve protective reflexes in the human respiratory tract.

\section{Sensory hyperresponsiveness}

Airway inflammation or chronic irritation with, for example, cigarette smoke may lead to hyperactivity in capsaicin sensitive afferent nerves, as seen in animal experiments. Prolonged exposure (for 14 days) of guinea pigs to cigarette smoke caused an enhanced sensitivity to the tussive effect of citric acid and thus selectively increased the sensitivity and reactivity of capsaicin sensitive nerves mediating cough. ${ }^{47}$ The airway content of neuropeptides was increased concomitantly, ${ }^{47}$ but the bronchoconstrictor response was not altered with this treatment. These data indicate that chronic airway irritation may lead to the development of a sensory hyperresponsiveness that is distinct from bronchial hyperresponsiveness. Interestingly, inflammatory stimuli applied to the skin may increase the synthesis of tachykinins in sensory nerves and ganglia, ${ }^{489}$ and in experimental chronic arthritis and inflammatory bowel disease the density of substance $P$ immunoreactive nerves has been reported to be increased. ${ }^{50} 51$

Clinical observations support the existence of a sensory hyperresponsiveness: subjects with cough induced by angiotensin converting enzyme inhibitor, ${ }^{52}$ or with a chronic cough, ${ }^{53}$ as well as subjects with a chronic dry cough, ${ }^{54}$ have an enhanced responsiveness to the tussive effect of inhaled capsaicin without increased bronchoconstrictor responses. Cough is the most common symptom of airway disease, and in chronic obstructive airway disease and in viral infections of the upper respiratory tract part of the excessive coughing is due to a sensory hyperresponsiveness ${ }^{55}$ (also RW Fuller, personal communication).

It was recently shown that obstruction, rhinorrhoea, and sneezing in patients with nonallergic chronic rhinitis could be significantly reduced after local treatment with capsaicin aerosol that rendered the nerves tachyphylactic.5657 These clinical findings suggest an important role for tachykinin containing sensory nerves in chronic rhinitis.

Respiratory infections and various forms of sustained irritation of the respiratory tract may lead to neuropeptide synthesis and increased afferent activity with sensory hyperresponsiveness. Sensory hyperresponsiveness may explain some of the symptoms in patients with chronic non-productive cough and non-allergic chronic rhinitis (figure).

Therapeutic implications

The hypothesis that capsaicin sensitive

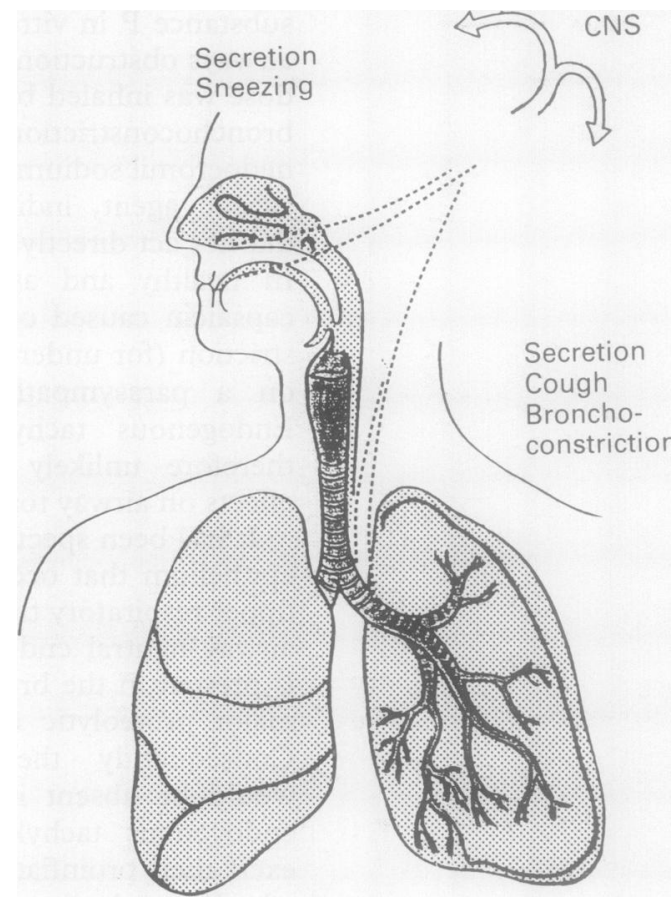

Diagram showing how irritation of sensory nerves (- - -) with endings in the human respiratory mucosa evokes protective reflexes. Capsaicin sensitive afferent nerves are carried mainly in the vagal and laryngeal nerves from the tracheobronchial tree and in the trigeminal nerve from the nose. Hyperactivity in sensory nerves, as in chronic nonproductive cough and non-allergic chronic rhinitis, may lead to sensory hyperresponsiveness.

sensory neurones may have an important role in reflexes protecting the airway and that chronic irritation may induce sensory hyperresponsiveness has therapeutic implications. At present antimuscarinic drugs, acting postjunctionally, are used to reduce mucus secretion and opiate antitussives to suppress activity in a "cough centre" in the central nervous system. It would be more attractive to inhibit afferent neural activity directly than to inhibit the effects of a range of released neuropeptides. In addition, because different respiratory reflexes have separate afferent neural pathways an improved efficacy and selectivity would be anticipated. Studies in patients with severe, chronic cough support this view: despite several treatments, including the use of high dose opiates, only inhaled local anaesthetics effectively suppressed coughing. ${ }^{5859}$ Similarly, induction of tolerance with topical capsaicin inhibited symptoms of chronic rhinitis. ${ }^{5657}$ Capsaicin treatment is painful and a drug inhibiting afferent pathways without having agonist activity obviously would be advantageous. It is tempting to suggest that respiratory symptoms during, for example, upper respiratory tract infections or whooping cough would also be reduced by this type of treatment. Afferent neural pathways in the respiratory tract thus provide new targets for rational drug design and possibly such drugs will become useful in the treatment of common illnesses of the respiratory tract. 
1 Coleridge HM, Coleridge JCG, Luck JC. Pulmonary afferent fibres of small diameter stimulated by capsaicin and by hyperinflation of the lungs. $\mathcal{F}$ Physiol (Lond) 1965;179:248-62.

2 Karlsson J-A, Sant'Ambrogio G, Widdicombe JG. Afferent neural pathways in cough and reflex bronchoconstriction. $\mathcal{F}$ Appl Physiol 1988;65:1007-23.

3 Lundberg JM, Saria A. Capsaicin induced desensitization of the airway mucosa to cigarette smoke, mechanical and chemical irritants. Nature 1983;302:251-3.

4 Karlsson J-A, Persson CGA. Evidence against vasoactive intestinal polypeptide (VIP) as a dilator and in favour of substance $\mathbf{P}$ as a constrictor in airway neurogenic responses. Br $\mathcal{F}$ Pharmacol 1983;79:634-6.

5 Barnes P, Baraniuk JN, Belvisi MG. Neuropeptides in the respiratory tract. Am Rev Respir Dis 1991;144:1187-98, 1391-9.

6 Karlsson J-A, Persson CGA. Novel peripheral neurotransmitters and control of the airways. Pharmac Ther 1989; 43:397-423.

7 Naline E, Devillier P, Drapeau G, Toty L, Bakdach H, Regoli D, et al Characterisation of neurokinin effects and receptor selectivity in human isolated bronchi. $\mathrm{Am}$ Rev Respir Dis 1989;140:6790-86.

8 Finney MJB, Karlsson J-A, Persson CGA. Effects of bronchoconstrictors and bronchodilators on a novel human small airway preparation. $\mathrm{Br} f$ Pharmacol 1985;85: 29-36.

9 Joos G, Pauwels R, Van Der Straeten M. Effect of inhaled substance $P$ and neurokinin $A$ on the airways of norma and asthmatic subjects. Thorax 1987;42:779-83.

10 Ollerenshaw SL, Jarvis DL, Sullivan CE, Woolcock AJ. Substance $P$ immunoreactive nerves in airways from asthmatics and non-asthmatics. Eur Respir 1991;4: 673-82.

11 Peters, MJ, Adcock IM, Gelder, CM, Shimasaki H, Belvisi MG, Yacoub $M$, et al $\mathrm{NK}_{1}$ receptor gene expression is increased in asthmativc lung and reduced by cor-
ticosteroids [abstract]. Am Rev Respir Dis 1992;145: A835.

12 Barnes PJ. Asthma as an axon reflex. Lancet 1986:242-4.

13 Nilsson G, Dahlberg K, Brodin E, Sundler F, Strandberg $K$. Distribution and constrictor effects of substance $P$ in guinea-pig tracheobronchial tissue. In: von Euler US, Pernow B, eds. Substance P. New York: Raven Press, 1977:57-61.

14 Lundberg JM, Hökfelt T, Martling C-R, Saria A, Cuello C. Sensory substance P-immunoreactive nerves in the lower respiratory tract of various mammals including man. Cell Tissue Res 1984;235:251-61.

15 Krause JE, Hershey AD, Dykema PE, Takeda Y. Molecular biological studies on the diversity of chemical signalling in tachykinin peptidergic neurons. Ann NY Acad Sci 1990;579:255-72.

16 Carstairs JR, Barnes PJ. Autoradiographic mapping of substance $P$ receptors in lung. Eur $\mathcal{F}$ Pharmacol 1986; 127:295-6.

17 Kröll F, Karlsson J-A, Lundberg JM, Persson CGA. Capsaicin-induced bronchoconstriction and neuropeptide release in guinea-pig perfused lungs. $\mathcal{F}$ Appl Physiol 1990;68:1679-87.

18 Nichol GM, Parsons GH, Barnes PJ, Chung KF. Effect of neuropeptides on bronchial blood flow and pulmonary resistance in conscious sheep [abstract]. Thorax 1989; 44:884P.

19 Alving K, Matran R, Lacroix JS, Lundberg JM. Allergen challenge induces vasodilation in pig bronchial circulation via a capsaicin sensitive mechanism. Acta Physiol Scand 1988;134:571-2.

20 Salonen RO, Webber SE, Widdicombe JG. Effects of neuropeptides and capsaicin on the canine tracheal vasculature in vivo. $B r \mathcal{F}$ Pharmacol 1988;95:1262-70.

21 Martling C-R, Gazelius B, Lundberg JM. Nervous control of tracheal blood flow in the cat measured by the laser doppler technique. Acta Physiol Scand 1987;130: 409-17.

22 Davies B, Roberts AM, Coleridge HM, Coleridge JCG. Reflex tracheal gland secretion evoked by stimulation of bronchial C-fibres in dogs. If Appl Physiol 1982;53: 985-91.

23 Ichinose $M$, Inoue $H$, Miura $M$, Yafuso $N$, Nogami $H$, Takishima $\mathrm{T}$. Possible sensory receptor of nonadrenergic inhibitory nervous system. F Appl Physiol 1987;63: 923-9.

24 Lundberg JM, Saria A, Lundblad L, Änggård A, Martling $\mathrm{CR}$, Theodorson-Norheim E, et al. Bioactive peptides in capsaicin-sensitive C-fiber afferents of the airways: functional and pathophysiological implications. In: Kaliner MA, Barnes PJ, eds. The airways. Neural control Kaliner MA, Barnes PJ, eds. The airways. Neural control
in health and disease. New York: Marcel Dekker, 1988: in health $417-445$.

25 Karlsson J-A, Persson CGA. Effects of different substance $P$ analogues on tachykinin-induced contraction of airway smooth muscle. In: Håkansson $R$, Sundler F, eds. Tachykinin antagonists. Amsterdam: Elsevier, 1985: 181-8.

26 Martling C-R, Theodorson-Norheim E, Lundberg JM. Occurrence and effects of multiple tachykinins: sub- stance $P$, neurokinin $A$ and neuropeptide $K$ in human lower airways. Life Sci 1987;40:1633-43.

27 Fuller RW, Maxwell DL, Dixon CMS, McGregor GP Barnes PJ, Bloom SR. Effect of substance P on cardiovascular and respiratory function in subjects $\mathcal{f} A p p l$ Physiol 1987;62:1473-9.

28 Joos GF, Pauwels RA, Van Der Straeten ME. The effect of nedocromil sodium on the bronchoconstrictor effect of neurokinin $\mathrm{A}$ in subjects with asthma. $\mathcal{F}$ Allergy Clin Immunol 1989;83:663-8.

29 Joos GF, Pauwels RA, Van Der Straeten ME. The effect of oxitropium bromide on neurokinin A-induced bronchoconstriction in asthmatics. Pulmon Pharmacol 1988; 1:41-5.

30 Fuller RW, Dixon CMS, Barnes PJ. The bronchoconstrictor response to inhaled capsaicin in humans. $\mathcal{f} A p p l$ Physiol 1985;85:1080-4.

31 Cheung D, Bel EH, Den Hartigh J, Dijkman JH, Sterk PJ The effect of an inhaled neutral endopeptidase inhibitor, thiorphan on airway responses to neurokinin $\mathrm{A}$ in normal humans in vivo. Am Rev Respir Dis 1992 145: $1275-80$

32 Cheung D, Timmers MC, Bel EH, Den Hartigh J, Dijkman JH, Sterk PJ. An inhaled neutral endopeptidase inhibitor, thiorphan, enhances airway narrowing to neurokinin $A$ in asthmatic subjects in vivo [abstract]. Am Rev Respir Dis 1992;145:A682.

33 Nichol GM, O'Connor BJ, Lecomte JM, Chung KF, Barnes PJ. Effect of neutral endopeptidase inhibitor on airway function and bronchial responsiveness in asthmatic subjects. Eur $f$ Clin Pharmacol 1992;42: 491-4.

34 Garret C, Carruette A, Fardin V, Moussaoui S, Peyronel J-F, Blanchard J-C, et al Pharmacological properties of a potent and selective nonpeptide substance $P$ antagonist. Proc Natl Acad Sci (USA) 1991;88:10208-12.

35 Snider RM, Constantine JW, Lowe III JA, Longo KP, Lebel WS, Woody HA, et al A potent non-peptide antagonist of the substance $\mathrm{P}\left(\mathrm{NK}_{1}\right)$ receptor. Science 1991;251:435-7.

36 Devillier P, Dessanges JF, Rakotoshanaka F, Ghaem A, Boushey HA, Lockhart A, et al. Nasal response to substance $P$ and methacholine in subjects with and without allergic rhinitis. Eur Respir f 1988;1:356-61.

37 Geppetti P, Fusco BM, Mararini S, Maggi CA, Fanciullacci M, Sicuteri F. Secretion, pain and sneezing induced by the application of capsaicin to the nasal mucosa in man. Br $\mathcal{f}$ Pharmacol 1988;93:509-14.

38 Karlsson G, Pipkorn U, Andreasson L. Substance P and human nasal mucociliary activity. Eur $\mathcal{f}$ Clin Pharmacol 1986;30:255-7.

39 Stiärne $P$, Lundblad L, Lundberg JM, Änggård A. Capsaicin and nicotine-sensitive afferent neurones and nasal secretion in healthy human volunteers and in patients with vasomotor rhinitis. Br $\mathcal{F}$ Pharmacol 1989; 96:693-701.

40 Duner-Engström M, Fredholm BB, Larsson O, Lundberg JM, Saria A. Autonomic mechanisms underlying capsaicin induced oral sensations and salivation in man. $f$ Physiol 1986;373:87-96.

41 Bascom R, Kagey-Sobotka A, Proud D. Effect of intranasal capsaicin on symptoms and mediator release. F Pharmacol Exp Ther 1991;259:1323-7.

42 Lundblad L, Lundberg JM, Änggård A, Zetterstrom O. Capsaicin-sensitive nerves and the cutaneous allergy reaction in man. Allergy 1987;42:20-5.

43 Barnes PJ, Brown MJ, Dollery CT, Fuller RW, Heavey DJ, Ind PW. Histamine is released from skin by substance $P$ but does not act as the final vasodilator in the axon reflex. Br $\mathcal{F}$ Pharmacol 1986;88:741-5.

44 Forsberg K, Karlsson J-A, Theodorsson E, Lundberg JM, Persson CGA. Cough and bronchoconstriction mediated by capsaicin-sensitive sensory neurons in guinea pigs. Pulmon Pharmacol 1988;1:33-9.

45 Karlsson J-A, Zackrisson C, Forsberg K. Inhibitors of ACE and enkephalinase potentiate irritant induced bronchoconstriction, but not cough, in conscious guinea pigs [abstract]. Br $\mathcal{F}$ Pharmacol 1988;96:158P.

46 Hansson L, Wollmer P, Dahlbäck M, Karlsson J-A. Regional sensitivity of human airways to capsaicininduced cough. Am Rev Respir Dis 1992;145:1191-5.

47 Karlsson J-A, Zackrisson C, Lundberg JM. Hyper-responsiveness to tussive stimuli in cigarette smoke-exposed guinea-pigs: a role for capsaicin-sensitive, calcitonin gene related peptide-containing nerves. Acta Physiol Scand 1991;141:445-54.

48 Colpaert FC, Donnerer J, Lembeck F. Effects of capsaicin in inflammation and on the substance $P$ content of nervous tissue in rats with adjuvant arthritis. Life Sci 1983, 32:1827-34.

49 Minami M, Kuraishi Y, Kawamura M, Yamaguchi T Masu Y, Nakanishi S, et al. Enhancement of preprotachykinin A gene expression by adjuvant-induced inflammation in the rat spinal cord: possible involvement of substance P-containing spinal neurons in nociception. Neurosci Lett 1989;98:105-10.

50 Holzer P. Local effector functions of capsaicin-sensitive sensory nerve endings: involvement of tachykinins, 
calcitonin gene related peptide and other neuropeptides. Neuroscience 1988;24:739-68.

51 Levine JD, Dardick SJ, Roizan MF, Helms C, Basbaum AI. Contribution of sensory afferents and sympathetic efferents to joint injury in experimental arthritis. $\mathcal{f}$ Neurosci 1986;6:3423-9.

52 Fuller RW, Choudry NB. Increased cough reflex associated with angiotensin converting enzyme inhibitor cough. BMF 1987;295:1025-6.

53 Hanson, L. Midgren B, Simonsson BG. Cough elicited by capsaicin in normal subjects and patients with chronic cough [abstract]. Bull Eur Physiopathol Respir 1987; 23(suppl 12):410S.

54 Fuller RW, Choudry NB. Patients with a non-productive cough have an increased cough reflex [abstract]. Thorax 1988;43:256.
55 Choudry NB, Fuller RW. Sensitivity of the cough reflex in patients with chronic cough. Eur Respir $\mathcal{F}$ 1992;5: 296-300.

56 Saria A, Wolfe G. Neue Aspekte zur Pathogenese und Therapie der hyperflektorischen Rhinopathie. Laryngorhinootologie 1988;67:438-45.

57 Lacroix JL, Buvelot JM, Polla BS, Lundberg JM. Improvement of symptoms of non-allerigc chronic rhinitis by local treatment with capsaicin. Clin Exp Allergy 1991;21:595-600.

58 Howard P, Cayton RM, Brennan SR, Anderson PB. Lignocaine aerosol and persistent cough. $\mathrm{Br} \mathcal{f}$ Dis Chest 1977;71:19-24.

59 Sanders RV, Kirkpatrick MB. Prolonged suppression of cough after inhalation of lidocaine in a patient with sarcoidosis. $¥ A M A$ 1984;252:2456-7. 